\title{
BK virus encephalopathy and sclerosing vasculopathy in a patient with hypohidrotic ectodermal dysplasia and immunodeficiency
}

Armine Darbinyan ${ }^{1}$, Eugene O. Major², Susan Morgello ${ }^{1,3,4}$, Steven Holland ${ }^{5}$, Caroline Ryschkewitsch²,

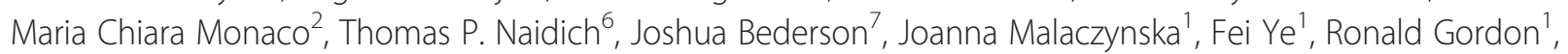
Charlotte Cunningham-Rundles ${ }^{8}$, Mary Fowkes ${ }^{1}$ and Nadejda M. Tsankova ${ }^{1,4^{*}}$

\begin{abstract}
Human BK polyomavirus (BKV) is reactivated under conditions of immunosuppression leading most commonly to nephropathy or cystitis; its tropism for the brain is rare and poorly understood. We present a unique case of BKV-associated encephalopathy in a man with hypohidrotic ectodermal dysplasia and immunodeficiency (HED-ID) due to IKK-gamma (NEMO) mutation, who developed progressive neurological symptoms. Brain biopsy demonstrated polyomavirus infection of gray and white matter, with predominant involvement of cortex and distinct neuronal tropism, in addition to limited demyelination and oligodendroglial inclusions. Immunohistochemistry demonstrated polyoma T-antigen in neurons and glia, but expression of VP1 capsid protein only in glia. PCR analysis on both brain biopsy tissue and cerebrospinal fluid detected high levels of BKV DNA. Sequencing studies further identified novel BKV variant and disclosed unique rearrangements in the noncoding control region of the viral DNA (BKV $N_{N}$ NCCR). Neuropathological analysis also demonstrated an unusual form of obliterative fibrosing vasculopathy in the subcortical white matter with abnormal lysosomal accumulations, possibly related to the patient's underlying ectodermal dysplasia. Our report provides the first neuropathological description of HED-ID due to NEMO mutation, and expands the diversity of neurological presentations of BKV infection in brain, underscoring the importance of its consideration in immunodeficient patients with unexplained encephalopathy. We also document novel $B K V_{N} N C C R$ rearrangements that may be associated with the unique neuronal tropism in this patient.
\end{abstract}

Keywords: Polyomavirus, BK virus, IKK-gamma, NF-kappa-B essential modulator (NEMO), Ectodermal dysplasia, HED-ID, Encephalopathy, Fibrosing vasculopathy

\section{Background}

Here we report the first histological description of BK virus encephalopathy with cortical predominance in a male patient with hypohidrotic ectodermal dysplasia and immunodeficiency (HED-ID), a rare X-linked disorder due to mutation in the NFkB signaling pathway.

\footnotetext{
* Correspondence: nadejda.tsankova@mssm.edu

${ }^{1}$ Department of Pathology, Icahn School of Medicine at Mount Sinai, New York 10029, NY, USA

${ }^{4}$ Department of Neuroscience and Friedman Brain Institute, Icahn School of Medicine at Mount Sinai, 1425 Madison Avenue, Icahn 9-20E, New York 10029, NY, USA

Full list of author information is available at the end of the article
}

Ectodermal dysplasias are a group of inherited disorders characterized by absence or dysplasia of ectodermal appendages. In the hypohidrotic form, there is abnormal development of eccrine sweat glands, teeth, and hair [23]. Mutations within a regulatory subunit of the NFkB pathway, IKK-gamma/NF-kappa-B essential modulator (NEMO), are known to cause two distinct $\mathrm{X}$-linked forms of ectodermal dysplasia: X-linked dominant familial incontinentia pigmenti (IP), which is typically fatal prenatally in males; and X-linked recessive disorder with rare combination of HED and immunodeficiency (HED-ID), in which incomplete loss of NEMO function leads to impaired immune response with recurrent 
bacterial and viral infections in addition to $\operatorname{HED}[2,17,21$, $30,46,50,59]$. Herein, we demonstrate BKV encephalopathy by histology, immunohistochemistry, sequencing, and further characterize a novel BKV variant $\left(B K V_{N}\right)$, which harbors unique rearrangements in the noncoding control region (NCCR), potentially contributing to its neuronal tropism. Finally, we describe several other previously unreported neuropathological features in this patient in the context of his underlying HED-ID disorder.

Polyomaviruses are non-enveloped, small $(\sim 40 \mathrm{~nm})$ viruses with a circular double-stranded DNA genome. BK polyomavirus (BKV) displays approximately $75 \%$ DNA homology with JC polyomavirus (JCV) and $70 \%$ homology with the simian polyomavirus SV40. Infection with BKV occurs during childhood and is usually asymptomatic. Thereafter, the virus enters a state of latency, predominantly in the renal tubular epithelial cells, during which BKV DNA can be detected, while viral proteins such as Tantigen, agnoprotein and capsid proteins, cannot. By adulthood, $80-90 \%$ of the general population is persistently colonized with BKV [31, 32]. Reactivation of the latent virus occurs predominantly in patients with impaired immune function, including HIV-1/AIDS, lymphoproliferative disorders and other malignancies, and treatment with immunosuppressive drugs [10,48]. The most common pathologic conditions associated with reactivation of BKV are polyomavirus-associated nephropathy or PVAN in kidney transplant recipients $[13,14,52]$ and hemorrhagic cystitis in bone marrow transplant recipients [3,31]. Less often, BKV is reported to cause fatal pneumonia, retinitis, native kidney nephritis, and only rarely meningoencephalitis in the severely immunocompromised [12, 16, 54]. JC polyomavirus, rather than $\mathrm{BK}$, is by far the most commonly associated virus with a CNS tropism in the context of immunosuppression, causing a progressive multifocal demyelinating leukoencephalopathy (PML) [29].

\section{Case presentation}

A 29-year-old man had been diagnosed with immunodeficiency at the age of one year after developing recurrent bacterial and viral infections in the setting of dysgammaglobulinemia with low levels of IgG. He also displayed signs of ectodermal dysplasia, including conical-shaped incisors, hypodontia and inadequate sweating. After multiple recurrent infections, at the age of 12 , the patient was diagnosed with HED-ID caused by NEMO deficiency. Genomic analysis revealed a missense mutation within the putative zinc-finger domain in the most $3^{\prime}$ exon of $I K K$ gamma - exon 10, causing a cysteine to arginine substitution $[2,59]$. Notably, the patient's older brother had very similar clinical presentation and passed away at the age of 17 with recurrent bronchiectasis after bilateral lung transplantation. Following diagnosis of HED-ID in the reported patient, lifelong IVIG treatment was initiated and maintained, leading to stabilization of IgG levels and a normal quality of life.

At the age of 29, the patient experienced new-onset neurological symptoms including left homonymous hemianopsia and intermittent, pressure-like headache, without significant motor, sensory, or cognitive impairment. Initial MRI of the brain (Fig. 1a, b) showed multiple scattered foci of increased T2 FLAIR signal, restricted diffusion, and contrast enhancement, predominantly within the right occipital lobe (likely contributing to the patient's visual changes). Additional small foci of increased T2 FLAIR signal were seen within the left frontal lobe, left thalamus, left pons and medulla. The varied, bilateral sites of radiographic abnormality suggested a possible embolic process, but infectious and non-infectious inflammatory processes were also considered in the differential. Extensive imaging workup failed to reveal an embolic source, and cultures of blood, urine, and cerebrospinal fluid (CSF) did not demonstrate bacterial, viral or fungal organisms. The patient's neurological status continued to deteriorate over the next 3 months with progressive disorientation and cognitive decline. Follow-up MRIs now showed further disease progression with more extensive involvement of both occipital lobes, prominent involvement of the cortex and subcortical white matter of both frontal lobes (Fig. 1c, d), and expanded involvement of the left thalamus and brainstem (Fig. 1e). CSF studies remained negative for bacteria, fungal elements, and a variety of viral pathogens (adenovirus, enterovirus, HSV1, HSV2, CMV, VZV, EBV, HHV6, and West Nile, East Equine encephalitis, and St. Louis encephalitis arboviruses). CSF PCR for JCV was negative on two separate occasions. Approximately three months after initial presentation, a targeted right occipital brain biopsy was performed for definitive diagnosis.

Histological examination of the biopsy specimen revealed a chronic inflammatory process involving the leptomeninges, underlying cortex and white matter (Fig. 2). The neocortex appeared distinctly abnormal, with widespread architectural neuronal disorganization, vacuolization most prominent in the external pyramidal layer III, reactive vasculature, astrogliosis and microglial activation (Fig. 2a-f). Many cortical neurons showed bizarre dysmorphic features, including increased size, displaced Nissl substance, vacuolization, and clustering (Fig. $2 \mathrm{~b}, \mathrm{~d}$ ), abnormal neurofilament accumulation in the cell body (Fig. 2e), and occasionally tuft-like ramified CD34-positive processes (Fig. 2f). In the subcortical white matter there was robust multifocal vacuolization (Fig. 2g-j) with minimal associated myelin loss (Fig. $2 \mathrm{~h}, \mathrm{j}$ ), and a prominent chronic perivascular and intraparenchymal inflammatory infiltrate composed of CD68+ macrophage/microglia and CD3+ T-lymphocytes (Fig. 2k-m). Scattered bizarre oligodendroglial-like cells with enlarged nuclei were noted, frequently containing glassy, homogeneous nuclear inclusions (Fig. 2i, 


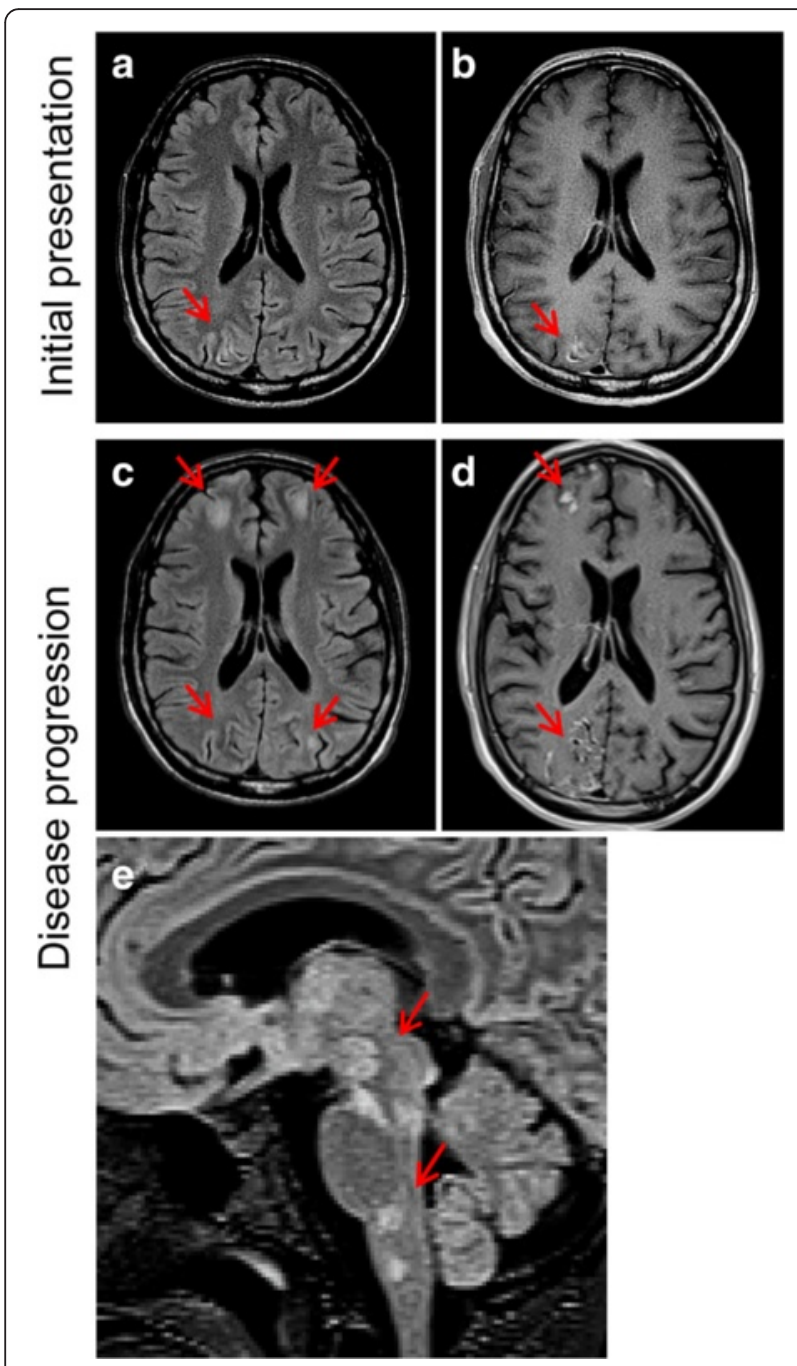

Fig. 1 Serial axial T2 FLAIR MRI (a, c) and corresponding axial contrast-enhanced T1 MRI (b, d) imaging of patient during initial presentation and after three months of disease progression when biopsy was performed. a Initial MRI (Day 1 of hospitalization) shows cortical gray matter with increased T2 FLAIR signal that is most prominent in the right occipital lobe (arrow) and just appreciable in the left occipital lobe. The related sulci are prominent, not compressed. The juxta-cortical white matter appears normal. b There is prominent contrast enhancement of portions of the affected cortices with no leptomeningeal enhancement. c-d Surveillance axial T2 FLAIR MRI (c, Day 90 of hospitalization,) and contrast-enhanced T1 MRI (d, Day 82 of hospitalization,) show disease progression with prominent involvement of both occipital and both frontal lobes. e T2 MRI through the deep gray matter and brain stem (sagittal) on Day 81 of hospitalization demonstrates patchy regions with signal abnormality in the basal ganglia, thalami and brain stem, including the medial left thalamus, right lateral geniculate nucleus, inferior colliculus, interpeduncular nuclei, dorsal pontine nuclei, and lateral medullary nuclei

arrows); Creutzfeldt-like astrocytes were also seen (Fig. 2j, arrowhead).

Immunohistochemical studies with anti-SV40 T-Antigen, which cross-reacts with $\mathrm{JC}$ and $\mathrm{BK}$ virus T-antigens, showed strong nuclear positivity in cortical neurons, predominantly in layers II-V (Fig. 3a) as well as in scattered enlarged oligodendroglial and astrocytic nuclei with bizarre multilobated appearance (Fig. 3b). The predominant morphology of infected cells in the cortex resembled pyramidal neurons, although infection of other neuronal cell populations could not be excluded. SV40 T-antigen was not identified in the leptomeninges, which otherwise appeared markedly fibrotic and expanded by chronic inflammatory infiltrate (Fig. 2a, c).

We also analyzed expression of the polyomavirus VP1 capsid protein using an antibody that cross-reacts with VP1 of JCV, BKV and SV40. Intriguingly, the number of cells positive for VP1 was significantly lower compared to T-antigen positive cells in the same region (Fig. 3c-d). Noticeably, VP1-immunoreactivity was associated with cells of oligodendroglial or astrocytic phenotype (Fig. 3d) but was largely absent in infected neurons (Fig. 3c). Electron microscopy confirmed the presence of 30$40 \mathrm{~nm}$ non-enveloped icosahedral viral particles within the nuclear chromatin, consistent with polyomavirus (Fig. 3e-f).

Detection of JC virus DNA by PCR, the most common polyomavirus to infect the brain, was unsuccessful both in CSF prior to the brain biopsy as well as in the pathological cortical tissue. We therefore considered the possibility of infection by other polyomavirus species, and performed targeted qPCR for BKV at the CLIA/NINDS laboratory [45], which detected a high titer of $\mathrm{BK}$ virus within the CSF and biopsy tissue.

The double-stranded circular DNA of the BKV genome contains approximately 5100 base pairs arranged around the cellular histones and is comprised of three parts: the early and late coding regions for regulatory and structural proteins that are transcribed in opposite directions, and a bidirectional NCCR located between the early and late coding regions. The early coding region encodes the regulatory proteins large and small tumor antigens, the truncated tumor antigen and a pre-miRNA for two miRNAs [1, 47]. The late coding region encodes the regulatory agnoprotein and the three structural capsid proteins VP1, VP2 and VP3. The NCCR controls the initiation of viral DNA synthesis and regulates the transcription of early and late promoters $[18,57]$. To further analyze the VP1 and NCCR regions of our specific BKV variant for sequence motifs in the context of its unique neuronal tropism, we performed a two-step nested PCR amplification followed by Sanger sequencing of BKV VP1 and NCCR (Fig. 4, Additional file 1: Figure S1). The major capsid protein of BK virus, VP1, is involved in the interaction with host cellular receptors [42], but whether specific VP1 polymorphisms are linked to neurological sequelae of BKV is not clear. The NCCR region of BKV contains binding motifs for numerous cellular transcription 


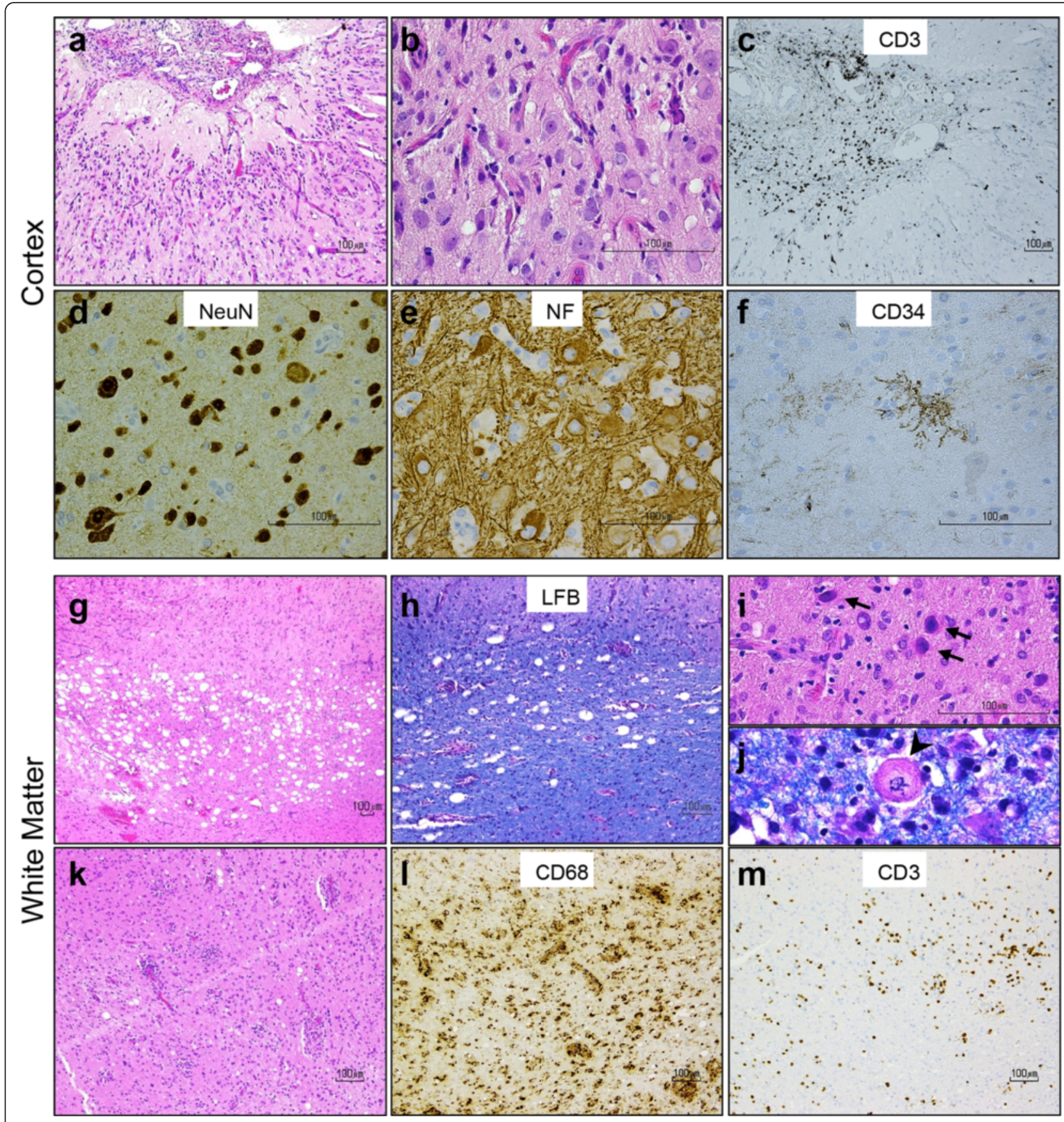

Fig. 2 Histological analysis of right occipital brain biopsy reveals unusual form of inflammatory encephalopathy. a-b Hematoxylin and eosin (H\&E) stains show chronic meningitis and neocortex with architectural neuronal disorganization, associated with reactive vasculature, gliosis, microglial activation, and mild chronic inflammation. c CD3+ T-lymphocytes predominate in the meninges. $\mathbf{d}$ Many cortical neurons display dysmorphic features, such as increased size, displaced Nissl substance, clustering, and e abnormal phosphorylated neurofilament accumulation in their cell body. f Tuft-like ramified CD34-positive processes are also seen in the neocortex. $\mathbf{g}$-j The subcortical white matter contains multifocal vacuolization associated with minimal myelin loss on luxol fast blue (LFB) stain, and scattered bizarre oligodendroglial-like cells with enlarged nuclei containing glassy, homogeneous nuclear inclusions (i, arrows) and Creutzfeldt-like astrocytes (j, arrowhead). $\mathbf{k}-\mathbf{m}$ Prominent chronic perivascular and intraparenchymal inflammatory infiltrate in the white matter is composed of CD68+ macrophage/microglia and CD3+ T-lymphocytes 


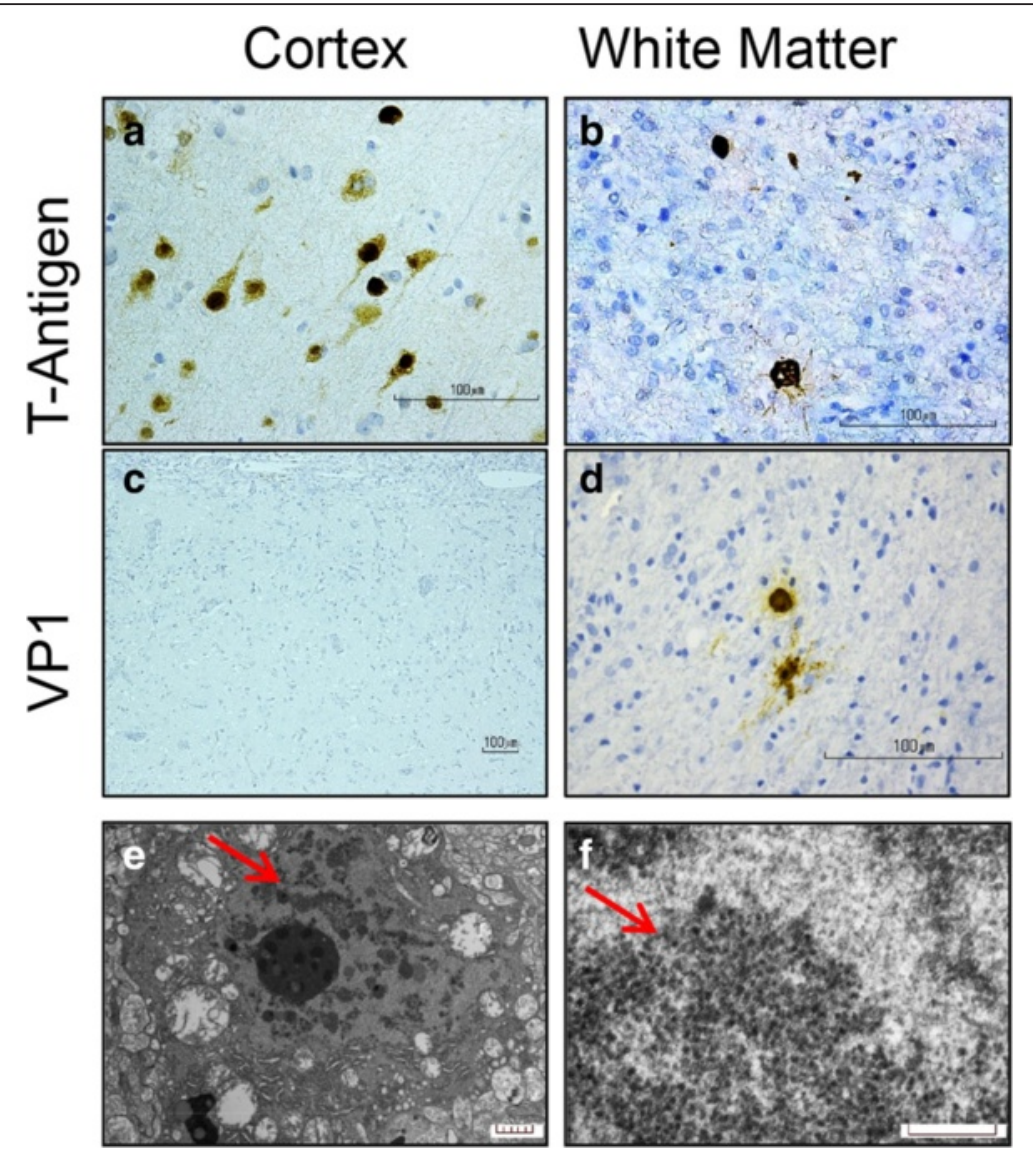

Fig. 3 Polyomavirus infection in cortex and white matter by immunohistochemistry and electron microscopy. a-b Immunostaining with the cross-reacting polyomavirus antibody anti-SV40 T-Antigen shows strong nuclear positivity in cortical neurons, predominantly in layers II-V (a) and in scattered enlarged oligodendroglial and astrocytic nuclei (b) in the white matter. c-d Immunoreactivity with the cross-reacting antibody anti-VP1 capsid protein is absent in cortical neurons (c) but is present in scattered cells with glial appearance in the white matter (d). e Electron micrographs reveal a neural cell with aggregates of spherical particles admixed with chromatin (arrow), scale bar $=5 \mu \mathrm{m}$. f At higher power, 30-40 nm in diameter non-enveloped icosahedral viral particles are observed, focally forming sheets and paracrystalline arrays (arrow); scale bar $=0.26 \mu \mathrm{m}$

factors (TFs) regulating viral transcription and replication $[11,36,57]$.

Sequence analysis of the patient's VP1-amplified fragment (Additional file 1: Figure S1) showed high homology (within a few single nucleotide variations) with BKV isolate RU15 (GenBank: FR720320.1; 2153 - 2583 nucleotides) and BKV Dunlop strain (GenBank: V01108.1; 2272 - 2697 nucleotides). The NCCR amplified fragment containing the initial portion of early genes (203 bp with start codon for large T-antigen) also showed high similarity to the Dunlop strain.

We also compared the sequence of our entire NCCR amplicon (432 bp) with the archetypal variant (non-rearranged, WW, GI:4838415). In the most frequently seen archetype BKV strain, NCCR has been arbitrarily divided into five sequence blocks denoted O-143, P-68, Q-39, R-63 and $\mathrm{S}-63$ where the numbers indicate base pairs $[40,41]$. Block $\mathrm{O}$ contains the origin of replication (ori) and binding sites for large T-antigen and TFs, including NFkB, CEBP $\beta$ and SP1 [57]. The early and late gene promoters and enhancers are located in $\mathrm{P}, \mathrm{Q}, \mathrm{R}$, and S blocks. The BKV NCCR in our patient harbored significant deviations from reported NCCR sequences, including four repeats of portions of block P (two $\Delta \mathrm{P} 41$ and two $\Delta \mathrm{P} 26$ ) in addition to a small insertion, deletions and single nucleotide variations. Block O, in contrast, was conserved (Fig. 4). The P blocks in our patient appeared in two variants consisting of 41 $(\triangle \mathrm{P} 41)$ and $25(\Delta \mathrm{P} 26)$ nucleotides. Each of these blocks encompassed the initial portions of $P$ block of archetype. The $\mathrm{P}$ blocks were arranged in the alternating manner: $\Delta \mathrm{P} 41+\Delta \mathrm{P} 26$ followed by small adenine-rich fragment and the second $\Delta \mathrm{P} 41+\Delta \mathrm{P} 26$. After the second $\Delta \mathrm{P} 26$, blocks $\mathrm{Q}$ and $\mathrm{R}$ were present, although with nucleotide variations and deletions. Block $\mathrm{S}$ was not identified, although we cannot exclude the possibility that this region failed to amplify (Fig. 4b). We also compared our sequence with previously reported rearranged BKV isolates and observed the highest homology with NCCR of BKV strains WWM13 (GenBank: 


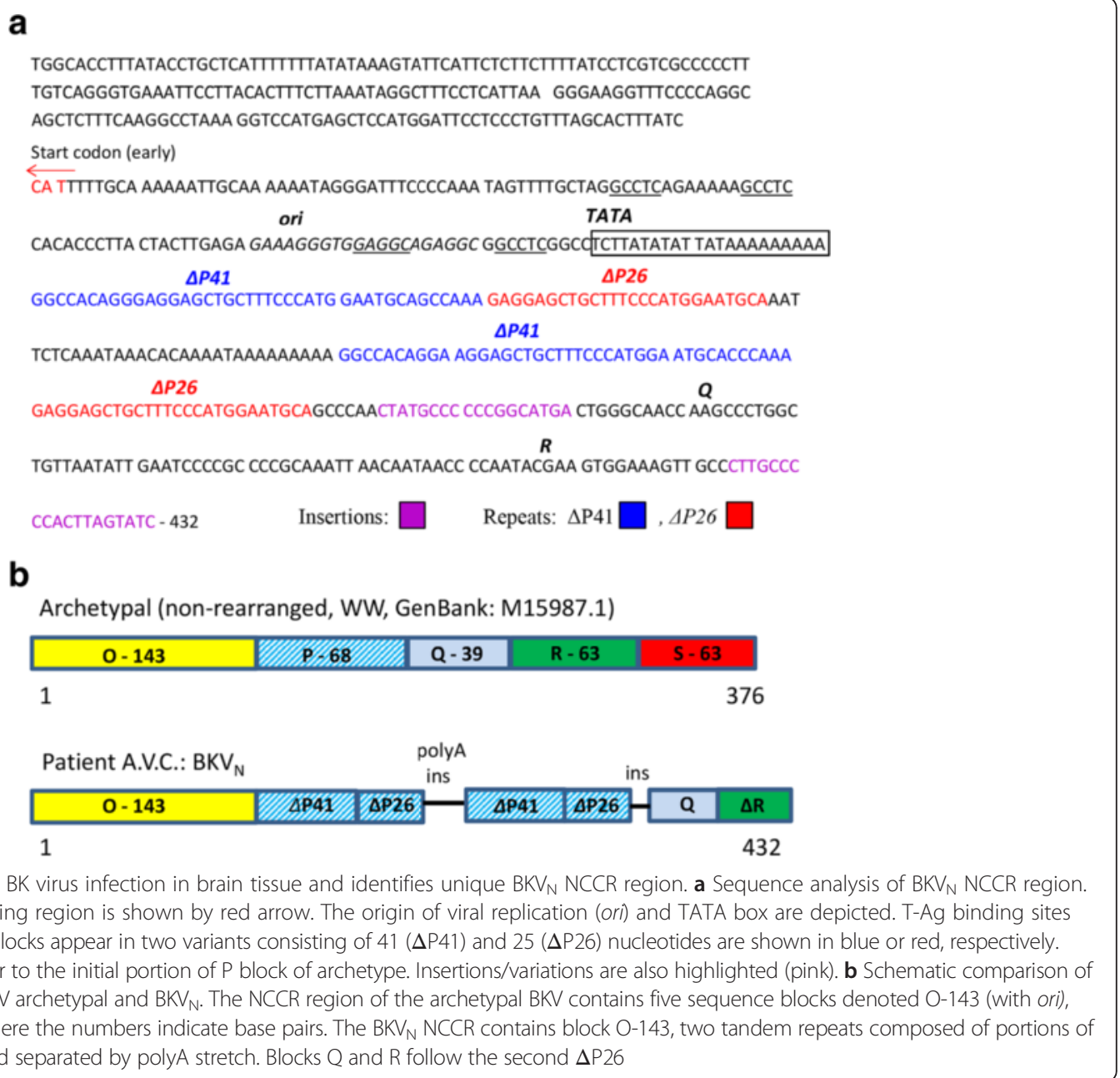

JQ513604.1) and WWM9 (GenBank: JQ513600.1). Intriguingly, these strains were isolated from the CSF of patients with neurological symptoms [4], implicating a possible association between these BKV rearrangements and predilection for CNS infection.

Detailed neuropathological analysis also demonstrated an unusual form of sclerosing vasculopathy in the white matter (Fig. 5), adjacent to but not involved by areas of inflammation and viral infection. We noted several thickened vessels whose walls were entirely replaced by concentric layers of collagen with uniquely associated perivascular lamellar fibrosis (Fig. 5d-e). These vessels lacked smooth muscle fibers in their walls (Fig. 5c), and their lumina were often completely obliterated with attempt at recanalization (Fig. 5b). The vascular fibrosis showed unusual extension into the adjacent brain parenchyma, revealing a dense, reticulin-rich scar (Fig. 5e) almost completely devoid of axonal processes. This angiocentric sclerosing process appeared on a continuum, with some vessels outside of the end-stage scar lesion showing milder collagen deposition with preserved lumina and smooth muscle walls, but with perivascular hemosiderin deposition, indicative of compromised vascular wall integrity (Fig. 5b, inset). Small caliber vessels with aberrant accumulation of lysosomal material were identified on electron microscopy (Fig. 5f, arrow).

\section{Discussion}

We report a very unusual presentation of BK virus encephalopathy in a patient with rare immunodeficiency and ectodermal dysplasia due to NFkB dysfunction and provide the first documented neuropathological description of this rare disorder, including the presence of unique form of sclerosing vasculopathy.

To our knowledge, this is the first histological demonstration that BK virus can infect cortical neurons in man, causing overwhelming encephalopathy with minimal demyelination. CNS infection by BK virus is unusual and clinically under-recognized, although a review of the literature reveals descriptions of BKV-associated encephalitis [7-9, 24, 35, 38, 55], meningoencephalitis $[12,51,53,54]$, PML $[15,19]$, and retinitis $[12,26]$. A single report describes the neuropathological alterations 

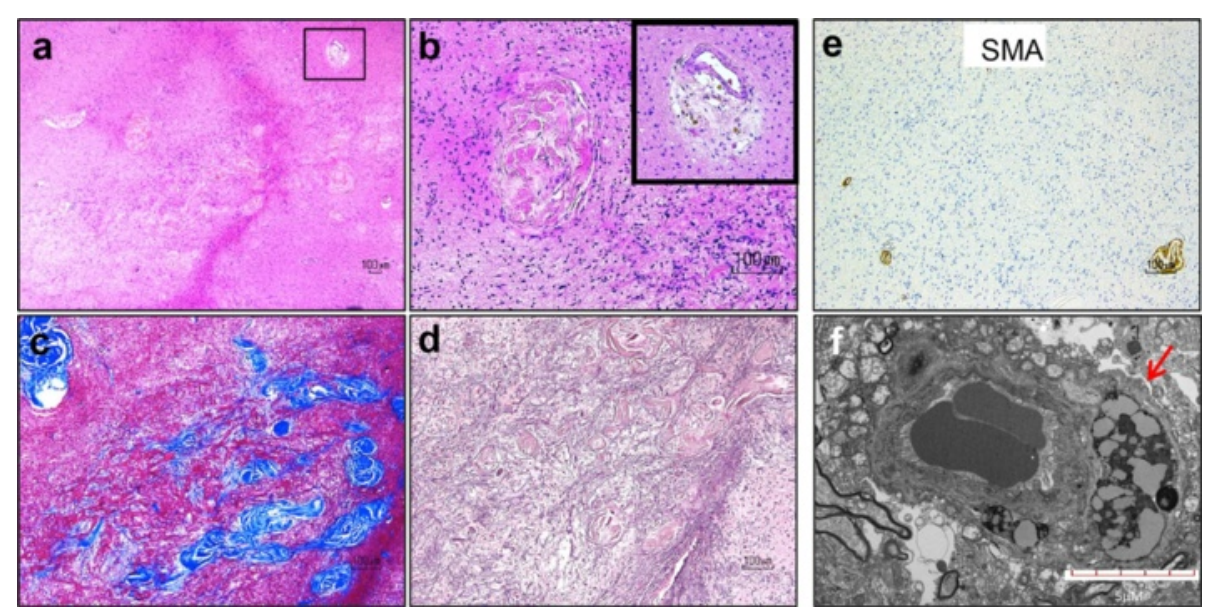

Fig. 5 Unusual form of sclerosing vasculopathy in HED-ID. a-b Hematoxylin and eosin stain shows vessels in the white matter with variably obliterated lumina, hyalinization, and perivascular hemosiderin deposits (inset in b). c-d Concentric lamellated pattern of collagen accumulation is seen on trichrome (c), extending into the adjacent brain parenchyma and forming a reticulin-rich scar (d). e Sclerotic vessels lack smooth muscle fibers in their walls. $\mathbf{f}$ EM shows capillary vessel with aberrant accumulation of lysosomes (arrow); scale bar $=5 \mu \mathrm{m}$

caused by BKV in the brain as marked perivascular and leptomeningeal lymphocytic infiltration and patches of demyelination and gliosis [38]. These elements were also present in our patient. Previous reports based on neuroimaging studies suggest that BKV infection has a predilection for the periventricular and pial surfaces of the brain parenchyma, with the cortex being spared [37]. Our case clearly demonstrates that BKV can also infect cortical neurons leading to progressive encephalopathic symptomatology, with only minimal demyelinating component at the time of biopsy. Indeed, numerous pyramidal cortical neurons in the occipital cortex of our patient showed strong positivity for polyomavirus $\mathrm{T}$-antigen but lacked staining for VP1 capsid protein. Among polyomaviruses, the most common one to infect the brain is JCV, which typically causes a demyelinating disease with a productive and lytic infection of oligodendrocytes and less commonly astrocytes $[10,20,44]$. Although predominant neuronal infection is rare, it has been reported in cerebellar granule cell neurons as JC virus granule cell neuronopathy (JCV$\mathrm{GCN}$ ), which is associated with JCV variants harboring a small deletion in the VP1 capsid protein [22,33], and in cortical pyramidal neurons as JCV encephalopathy (JCV-E), which is caused by JCV variants containing Agno deletions [58]. Interestingly, in JCV-E more neurons are positive for T-antigen, than for VP1 capsid protein, and it has been suggested that this phenomenon is due to latent, recent, or abortive infection [58]. Similar findings were reported in the occipital and temporal cortices of a 21-year-old patient with common variable immunodeficiency, where the presence of JCV T-antigen and P53, but not VP1 capsid protein, was detected in dysplastic ganglion-like cells [49]. Overall, our findings corroborate that polyomaviruses can infect neurons, and underscore the importance of considering BKV infection in the differential diagnosis of immunosuppressed patients with clinical symptoms of encephalopathy with undetectable JCV in their CSF.

Furthermore, we have identified a new BKV isolate with significant rearrangements in its NCCR, which likely contributed to the reactivation of the virus, in agreement with numerous studies showing that the most rearranged strains with deletions, insertions and duplications in NCCR are associated with increased viral replication [25, 43]. We speculate that the activation of BKV in an unusual host compartment - here the neuronal cell - is dependent on these unique NCCR rearrangements. This novel strain has a quadruple enhancer element containing imperfect duplications of an archetypal P element. One possible mechanism for viral activation and/or neuronal tropism may be through selective amplification of TF motifs in this amplified P NCCR region, such as nuclear factor 1 (NF1) or SP1, leading to transcriptional activation of viral genes necessary for replication and/or neuronal infectivity. Further studies are needed to characterize the exact role NCCR rearrangements may play in BKV activation and neuronal tropism, and the regulatory networks involved, which are beyond the scope of this report.

Our detailed neuropathological analysis uncovered two additional unusual features in the brain of this patient with HED-ID, which may be related to his underlying ectodermal dysplasia. The first one was the widespread presence of dysplastic neurons throughout the occipital cortex biopsy specimen. Many of these neurons showed T-antigen immunoreactivity, suggesting that BKV infection may account for their dysmorphic appearance. Intriguingly, many neurons immunoreactive for large $\mathrm{T}$ antigen were also positive for $\mathrm{p} 53$, but not for capsid protein VP1. Previous 
studies have suggested a possible role of T-antigen in the dysplastic, ganglion cell-like change of the JCV infected cortical neurons [49]. However, we found that more neurons appeared dysplastic than showed immunohistochemical evidence of infection, raising the additional possibility of an underlying cortical dysplasia superimposed on polyomavirus infection in this patient. In the absence of previous reports on the neuropathological effect of NEMO or BKV on neurons and without further mechanistic studies, it is not feasible to relate unequivocally the presence of abnormal/dysplastic neurons to either BKV-associated cytopathic effect or to HED-ID. The effect of NEMO deficiency on cortical neuronal development has not been previously scrutinized and it deserves further consideration.

We also uncovered a unique sclerosing vasculopathy. The fibrosing process had notable predilection for medium sized vessels in the white matter, and manifested with obliteration of the vessel lumen and deposition of perivascular collagen in a lamellated pattern, which extended into the surrounding brain parenchyma. As well, abnormal accumulation of lysosomal material was noted within the walls of some small-caliber vessels, which may be secondary to hypoxic stress or alternatively relate to a degenerative process. To our knowledge, the appearance of this angiocentric fibrotic scar has not been previously described in other CNS vasculopathic processes. We believe it represents unique dysplastic pathology related to the patient's underlying ectodermal dysplasia and herein provide its first neuropathological depiction in a male patient with NEMO-deficiency.

There is very limited number of reports on the pathology of HED-ID. The first comprehensive study to describe pathological findings in 13 patients with HED-ID (biopsies and autopsies) did not disclose any neuropathological abnormalities or features specific to NEMO deficiency [28]. CNS findings in this study included agenesis of the corpus callosum in one child, moderate-to-severe cerebral atherosclerosis and hipopigmented substantia nigra in one adult, a remote cerebral cortical infarct, cortical ribbon defect and invasive cerebral aspergillosis in another adult, and subacute and chronic inflammation in the white matter of one living adult patient, without further histological analyses. Skin biopsies were also analyzed in this study, describing mainly inflammatory pathological findings (granulomatous dermatitis with positive AFB staining, lobular panniculitis, seborrheic keratosis, folliculitis) as well as abnormal vascular calcification in two patients; there was no mention of fibrosing vasculopathy and the presence of abnormal lysosomal accumulations were not assessed. While our report is the first to describe fibrosing vasculopathy in the brain of a patient with HED-ID, abnormalities in CNS vessels have been previously observed in patients with the closely related
NEMO-deficiency disorder in females, IP [6]. Brain MR imaging studies in patients with IP have demonstrated findings suggestive of microangiopathy [27, 34, 39]. Interestingly, vascular sclerosis and occlusion with associated fibrotic perivascular changes were reported in the retina of patients with IP [56]. The molecular mechanisms underlying these vascular changes are not known, but dysregulation of the NFkB signaling pathway is likely to play a role.

\section{Conclusion}

BK polyomavirus encephalopathy is not typically considered in the differential diagnosis of patients with neurological symptoms, and may be under-recognized in immunosuppressed patients. We suggest that screening for BKV in the CSF of patients with encephalopathy and undetectable JCV is of clinical importance. Our study provides detailed neuropathological description of the manifestation of BKV CNS infection with distinct neuronal tropism in a patient with NFkB-mediated immunosuppression, expanding its clinical recognition. The identified unique BKV sequence may be important for elucidating the mechanisms of BK viral reactivation and neurovirulence in future studies.

\section{Materials and methods \\ Antibodies}

Immunohistochemistry (IHC) was performed with the following antibodies: mouse monoclonal anti-NeuN (A60; MAB377; Chemicon), mouse monoclonal antiNeurofilament (2 F11, 760-2661, Ventana Medical Systems, Inc.), rabbit polyclonal anti- Glial Fibrillary Acidic Protein (GFAP) (EP672Y; 760-4345, Ventana Medical Systems, Inc.), mouse monoclonal anti-p53 (DO-7, 790-2912, Ventana Medical Systems, Inc.), rabbit monoclonal anti-CD3 (2GV6, 790-4341, Ventana Medical Systems, Inc.), mouse monoclonal anti-CD34 (QBEnd/10, 7902927, Ventana Medical Systems, Inc.), mouse monoclonal anti-CD68 (KP-1, 790-2931, Ventana Medical Systems, Inc.), SV40 T Ag (v-300; sc-20800, Santa Cruz Biotechnology, Santa Cruz, CA) rabbit polyclonal antibody (raised against amino acids 4-30 mapping near the N-terminus of SV40 T Ag). Anti-VP1 antibody (mouse serum ab 597) was kindly provided by Dr. Kamel Khalili (Department of Neuroscience, Temple University School of Medicine, Philadelphia, US).

\section{Immunohistochemical staining}

Paraffin embedded sections $(4 \mu \mathrm{M})$ fixed in $10 \%$ formalin were deparaffinized in xylene, with subsequent rehydration in a decreasing gradient of ethanol. Antigen retrieval was performed using cell-conditioning solution 1 (Ventana Medical Systems, AZ) for $60 \mathrm{~min}$ at $95{ }^{\circ} \mathrm{C}$. After blocking, sections were incubated with primary antibodies according 
manufacturer protocols. Sections were washed and incubated with mouse or rabbit secondary antibodies depending on the type of the primary antibody on automated strainers at room temperature (Ventana XT). Immunoreactivity was detected by means of the IVIEW or Ultraview Universal DAB Detection Kits (760-500, Ventana Medical Systems, AZ).

\section{Electron microscopy}

Small pieces of brain tissue were received fixed in $3 \%$ glutaraldehyde in a $0.2 \mathrm{M}$ sodium cacodylate buffer at $\mathrm{pH}$ 7.4. The tissue was treated with osmium tetroxide for one hour rinsed in $0.2 \mathrm{M}$ sodium cacodylate buffer and then subjected to dehydration in increasing steps of ethanol through propylene oxide and embedded in embed 812. One-micrometer plastic sections were cut, stained with methylene blue and Azure II, and observed by light microscopy. Representative areas were chosen for ultrathin sectioning. The thin sections were stained with uranyl acetate and lead citrate and photographed with a Hitachi H7650 transmission electron microscope equipped with an SIA digital imaging system.

\section{DNA isolation and sequencing DNA extraction}

DNA extraction was performed from $40 \mu \mathrm{l}$ of fresh frozen brain tissue using Qiagen QIAamp DNA kit (Cat. \#51304) and Qiagen ATL Buffer (Cat. \#19076) according to the manufacturer's instructions. RNA Carrier (Qiagen Cat. 1068337) was added to the sample to optimize DNA yield. The DNA was eluted in a volume of $45 \mu \mathrm{l} \mathrm{AE}$ Buffer and its concentration was measured using NanoDrop 2000.

Nested PCR amplification of VP1 and NCCR sequences of BKV was performed as previously described $[4,5]$, with slight modifications. Positions of nucleotides for all primers are shown based on nucleotide sequence in BKV Dunlop strain, V01108.

\section{Amplification of the BKV VP1 region (nt 1456-2744)}

In the first reaction, the following primers were used: forward VP1-F1 5' -AAACTATTGCCCCAGGAGGT-3' (nucleotides (nt) 1456-1475) and reverse VP1-R4 5' -CTAA AACACCACCCCCAAAA-3' (nt 2725-2744). A 1289 bp PCR products were purified by gel extraction using Qiagen QIAquick gel extraction kit (Qiagen, Cat. 28704) and used for nested PCR with the following primers: forward VP1-F4 5'-CTAATCAAAGAACTGCTCCTCAA TG-3' (nt 1477-1501) and reverse VP1-R8 5'-ACCACC CCCAAAATAACACA-3' (nt 2718-2737), producing an amplicon of $1261 \mathrm{bp}$. Both reactions were performed in a volume of $50 \mu \mathrm{l}$ with $500 \mathrm{nM}$ of each primer, $5 \mathrm{mM} \mathrm{MgCl}_{2}$, $500 \mu \mathrm{M}$ dNTP's, and $1.25 \mathrm{U}$ of AmpliTaq Gold (ThermoFisher, Cat. N8080248) and nuclease-free water. The first
PCR was performed on $2 \mu \mathrm{l}$ eluted DNA. A $4 \mu \mathrm{l}$ of the first PCR product was used in the nested PCR. PCR conditions: denaturation - $15 \mathrm{~min}$ at $94{ }^{\circ} \mathrm{C}, 40$ cycles of $30 \mathrm{~s}$ at $94{ }^{\circ} \mathrm{C}$, $30 \mathrm{~s}$ at $55.7{ }^{\circ} \mathrm{C}\left(65^{\circ} \mathrm{C}\right.$ for the nested PCR $)$, and $60 \mathrm{~s}$ at $72{ }^{\circ} \mathrm{C}$ with a final extension of $7 \mathrm{~min}$ at $72{ }^{\circ} \mathrm{C}$.

\section{Amplification of the BKV NCCR region (nt 4881-680)}

In the first reaction, the following primers were used: forward ORIBK1 5' -ATCTGGGCAAAGAGGAAAATC A-3' (nt 4881-4902) and reverse ORIBK2 5'-AGCAG CCTCAGATACACTGG-3' (nt 661-680). Nested PCR was performed with Forward ORIBK3 5'-CAGGTT CCAAAATCAGGCTG-3' (nt 4924-4943) and reverse ORIBK 5 '-CTAGGAGTCTTTTACA-GAGTCT-3' (nt 567-588) primers. For both amplification reactions, AmpliTaq DNA polymerase with GeneAmp kit (ThermoFisher Cat. N8080248) including $1.25 \mathrm{U}$ of the polymerase were employed. A final volume of $50 \mu \mathrm{l}$ was completed with $500 \mathrm{nM}$ of each primer, $500 \mu \mathrm{M}$ of dNTPs, $5 \mathrm{mM}$ of $\mathrm{MgCl}_{2}$, nuclease-free water and $2 \mu \mathrm{l}$ of the DNA eluted (or $4 \mu \mathrm{l}$ of the first PCR product for the nested PCR). PCR conditions: denaturation $15 \mathrm{~min}$ at $95{ }^{\circ} \mathrm{C}, 40$ cycles of $30 \mathrm{~s}$ at $94{ }^{\circ} \mathrm{C}, 30 \mathrm{~s}$ at $56{ }^{\circ} \mathrm{C}\left(58{ }^{\circ} \mathrm{C}\right.$ for the nested PCR), and $1 \mathrm{~min}$ at $72^{\circ}$ with a final extension $7 \mathrm{~min}$ at $72{ }^{\circ} \mathrm{C}$. The amplicons were separated by electrophoresis on a $1 \%$ agarose gel in the presence of ethidium bromide and were visualized under UV light. To avoid contamination, ultrapure reagents were added under a laminar flow hood and in a separate room.

\section{Consent}

Informed consent was obtained from all individual participants included in the study.

\section{Additional file}

Additional file 1: Targeted sequencing strategy for BKV VP1 and NCCR regions. a. Products of nested PCR encompassing 1265 bp of BKV VP1 and $800 \mathrm{bp}$ of NCCR with initial portion of early coding region are purified from an $1 \%$ agarose gel and submitted to Sanger sequencing. b. Sanger sequencing results of VP1 and NCCR purified gel products. (PDF 427 kb)

\section{Acknowledgments}

We thank the family, as well as the physicians who assisted in gathering clinical information and samples. We are grateful to Dr. Schein for the Neuropathology Endowed Fellowship award to Dr. Darbinyan A. We thank Dr. Kamel Khalili and Dr. Jennifer Gordon from the Department of Neuroscience and Center for Neurovirology, Temple School of Medicine, Philadelphia, PA for their insightful discussion and sharing of reagents.

\section{Authors' contributions}

AD participated in the neuropathological diagnosis, carried out viral DNA isolation from the frozen brain tissue and BKV genome characterization, analyzed the results of all studies, and wrote the manuscript. EOM, CR, and MCM first identified BKV in brain tissue by PCR. SM contributed to conceptualizing BKV encephalopathy and participated in the comprehensive analysis of the results. EOM and SM contributed significantly to the final manuscript. TPN analyzed the neuro-imaging studies. RG carried out electron microscopy studies. MF participated in the histopathology analysis. JM and 
FY helped with BKV isolation and downstream molecular studies. CC-R, JB and $\mathrm{SH}$ participate in the clinical care of the patient and provided clinical follow up. NMT formulated the neuropathological diagnosis, led the analysis of the results, designed the report, and constructed the final manuscript. All authors contributed to and approved the final manuscript.

\section{Competing interests}

The authors declare that they have no competing interests.

\section{Author details}

${ }^{1}$ Department of Pathology, Icahn School of Medicine at Mount Sinai, New York 10029, NY, USA. ${ }^{2}$ Laboratory of Molecular Medicine and Neuroscience, National Institute of Neurological Disorders and Stroke, National Institutes of Health, Bethesda 20892, MD, USA. ${ }^{3}$ Department of Neurology, Icahn School of Medicine at Mount Sinai, New York 10029, NY, USA. ${ }^{4}$ Department of Neuroscience and Friedman Brain Institute, Icahn School of Medicine at Mount Sinai, 1425 Madison Avenue, Icahn 9-20E, New York 10029, NY, USA. ${ }^{5}$ Laboratory of Clinical Infectious Diseases, National Institute of Allergy and Infectious Diseases, National Institutes of Health, Bethesda 20892, MD, USA. ${ }^{6}$ Department of Radiology, Icahn School of Medicine at Mount Sinai, New York 10029, NY, USA. ${ }^{7}$ Department of Neurosurgery, Icahn School of Medicine at Mount Sinai, New York 10029, NY, USA. ${ }^{8}$ Department of Medicine - Allergy \& Immunology, Icahn School of Medicine at Mount Sinai, New York 10029, NY, USA.

\section{Received: 13 May 2016 Accepted: 26 June 2016}

Published online: 13 July 2016

\section{References}

1. Abend JR, Joseph AE, Das D, Campbell-Cecen DB, Imperiale MJ. A truncated $T$ antigen expressed from an alternatively spliced BK virus early mRNA. J Gen Virol. 2009;90:1238-45. doi:10.1099/vir.0.009159-0.

2. Aradhya S, Courtois G, Rajkovic A, Lewis RA, Levy M, Israel A, Nelson DL. Atypical forms of incontinentia pigmenti in male individuals result from mutations of a cytosine tract in exon 10 of NEMO (IKK-gamma). Am J Hum Genet. 2001;68:765-71. doi:10.1086/318806.

3. Azzi A, Cesaro S, Laszlo D, Zakrzewska K, Ciappi S, De Santis R, Fanci R, Pesavento G, Calore E, Bosi A. Human polyomavirus BK (BKV) load and haemorrhagic cystitis in bone marrow transplantation patients. J Clin Virol. 1999:14:79-86.

4. Barcena-Panero A, Echevarria JE, Van Ghelue M, Fedele G, Royuela E, Gerits N, Moens U. BK polyomavirus with archetypal and rearranged non-coding control regions is present in cerebrospinal fluids from patients with neurological complications. J Gen Virol. 2012;93:1780-94. doi:10.1099/vir.0. 042143-0.

5. Barcena-Panero A, Van Ghelue M, Khan MT, Echevarria JE, Fedele G, Moens U. BK virus-associated infection in cerebrospinal fluid of neurological patients and mutation analysis of the complete VP1 gene in different patient groups. J Cell Physiol. 2012;227:136-45. doi:10.1002/jcp.22711.

6. Beccastrini E, Baldereschi G, D’Elios MM, Emmi L. Arterial occlusion mimicking vasculitis in a patient with incontinentia pigmenti. Auto- immunity highlights. 2013;4:63-5. doi:10.1007/s13317-013-0050-y.

7. Behre G, Becker M, Christopeit M. BK virus encephalitis in an allogeneic hematopoietic stem cell recipient. Bone Marrow Transplant. 2008;42:499. doi:10.1038/bmt.2008.198.

8. Behzad-Behbahani A, Klapper PE, Vallely PJ, Cleator GM. BK virus DNA in CSF of immunocompetent and immunocompromised patients. Arch Dis Child. 2003:88:174-5.

9. Behzad-Behbahani A, Klapper PE, Vallely PJ, Cleator GM, Bonington A. BKV-DNA and JCV-DNA in CSF of patients with suspected meningitis or encephalitis. Infection. 2003;31:374-8. doi:10.1007/s15010-003-3078-5.

10. Berger JR, Concha M. Progressive multifocal leukoencephalopathy: the evolution of a disease once considered rare. J Neurovirol. 1995;1:5-18.

11. Bethge T, Hachemi HA, Manzetti J, Gosert R, Schaffner W, Hirsch HH. Sp1 sites in the noncoding control region of BK polyomavirus are key regulators of bidirectional viral early and late gene expression. J Virol. 2015;89:3396-411. doi:10.1128/jvi.03625-14.

12. Bratt G, Hammarin AL, Grandien M, Hedquist BG, Nennesmo I, Sundelin B, Seregard S. BK virus as the cause of meningoencephalitis, retinitis and nephritis in a patient with AIDS. AIDS (London, England). 1999;13:1071-5.
13. Brennan DC, Agha I, Bohl DL, Schnitzler MA, Hardinger KL, Lockwood M, Torrence S, Schuessler R, Roby T, Gaudreault-Keener M, Storch GA. Incidence of BK with tacrolimus versus cyclosporine and impact of preemptive immunosuppression reduction. Am J Transplant Off J Am Soc Transplant Am Soc Transplant Surg. 2005;5:582-94. doi:10.1111/j.1600-6143.2005.00742.x.

14. Bressollette-Bodin C, Coste-Burel M, Hourmant M, Sebille V, Andre-Garnier E, Imbert-Marcille BM. A prospective longitudinal study of BK virus infection in 104 renal transplant recipients. Am J Transplant Off J Am Soc Transplant Am Soc Transplant Surg. 2005;5:1926-33. doi:10.1111/j.1600-6143.2005.00934.x.

15. Cabrejo L, Diop M, Blohorn-Sense A, Mihout B. Progressive BK virus associated multifocal leukoencephalopathy in an immunocompromised patient treated with corticosteroids. Rev Neurol. 2005;161:326-30.

16. Chittick P, Williamson JC, Ohl CA. BK virus encephalitis: case report, review of the literature, and description of a novel treatment modality. Ann Pharmacother. 2013;47:1229-33. doi:10.1177/1060028013500646.

17. Courtois G, Israel A. IKK regulation and human genetics. Curr Top Microbiol Immunol. 2011;349:73-95. doi:10.1007/82_2010_98.

18. Cubitt CL. Molecular genetics of the BK virus. Adv Exp Med Biol. 2006;577: 85-95. doi:10.1007/0-387-32957-9_6.

19. Daveson KL, Ong CW, Bowden S, Koina ME, Hallam LA. BK virus-associated progressive multifocal leukoencephalopathy. Med J Aust. 2013;198:216-8.

20. Del Valle L, Croul S, Morgello S, Amini S, Rappaport J, Khalili K. Detection of HIV-1 Tat and JCV capsid protein, VP1, in AIDS brain with progressive multifocal leukoencephalopathy. J Neurovirol. 2000;6:221-8.

21. Doffinger R, Smahi A, Bessia C, Geissmann F, Feinberg J, Durandy A, Bodemer C, Kenwrick S, Dupuis-Girod S, Blanche S, Wood P, Rabia SH, Headon DJ, Overbeek PA, Le Deist F, Holland SM, Belani K, Kumararatne DS, Fischer A, Shapiro R, Conley ME, Reimund E, Kalhoff H, Abinun M, Munnich A, Israel A, Courtois G, Casanova JL. X-linked anhidrotic ectodermal dysplasia with immunodeficiency is caused by impaired NF-kappaB signaling. Nat Genet. 2001;27:277-85. doi:10.1038/85837.

22. Du Pasquier RA, Corey S, Margolin DH, Williams K, Pfister LA, De Girolami U, Mac Key JJ, Wuthrich C, Joseph JT, Koralnik IJ. Productive infection of cerebellar granule cell neurons by JC virus in an HIV+ individual. Neurology. 2003;61:775-82.

23. Freire-Maia N, Pinheiro M. Ectodermal dysplasias-some recollections and a classification. Birth Defects Orig Artic Ser. 1988;24:3-14.

24. Friedman DP, Flanders AE. MR Imaging of BK virus encephalitis. AJNR Am J Neuroradiol. 2006;27:1016-8.

25. Gosert R, Rinaldo CH, Funk GA, Egli A, Ramos E, Drachenberg CB, Hirsch HH. Polyomavirus BK with rearranged noncoding control region emerge in vivo in renal transplant patients and increase viral replication and cytopathology. J Exp Med. 2008;205:841-52. doi:10.1084/jem.20072097.

26. Hedquist BG, Bratt G, Hammarin AL, Grandien M, Nennesmo I, Sundelin B, Seregard S. Identification of BK virus in a patient with acquired immune deficiency syndrome and bilateral atypical retinitis. Ophthalmology. 1999; 106:129-32. doi:10.1016/s0161-6420(99)90014-3.

27. Hennel SJ, Ekert PG, Volpe JJ, Inder TE. Insights into the pathogenesis of cerebral lesions in incontinentia pigmenti. Pediatr Neurol. 2003;29:148-50.

28. Huppmann AR, Leiding JW, Hsu AP, Raffeld M, Uzel G, Pittaluga S, Holland SM. Pathologic Findings in NEMO Deficiency: A Surgical and Autopsy Survey. Pediatr Dev Pathol. 2015;18:387-400. doi:10.2350/15-05-1631-oa.1.

29. Imperiale MJ, Major EO. Fields Virology. Polyomaviruses. Philadelphia, PA: Lippincott Williams \& Wilkins; 2007.

30. Jain A, Ma CA, Liu S, Brown M, Cohen J, Strober W. Specific missense mutations in NEMO result in hyper-IgM syndrome with hypohydrotic ectodermal dysplasia. Nat Immunol. 2001;2:223-8. doi:10.1038/85277.

31. Jiang M, Abend JR, Johnson SF, Imperiale MJ. The role of polyomaviruses in human disease. Virology. 2009;384:266-73. doi:10.1016/j.virol.2008.09.027.

32. Kean JM, Rao S, Wang M, Garcea RL. Seroepidemiology of human polyomaviruses. PLoS Pathog. 2009;5:e1000363. doi:10.1371/journal.ppat.1000363.

33. Koralnik IJ, Wuthrich C, Dang X, Rottnek M, Gurtman A, Simpson D, Morgello S. JC virus granule cell neuronopathy: a novel clinical syndrome distinct from progressive multifocal leukoencephalopathy. Ann Neurol. 2005:57:576-80. doi:10.1002/ana.20431.

34. Lee AG, Goldberg MF, Gillard JH, Barker PB, Bryan RN. Intracranial assessment of incontinentia pigmenti using magnetic resonance imaging, angiography, and spectroscopic imaging. Arch Pediatr Adolesc Med. 1995;149:573-80.

35. Lesprit P, Chaline-Lehmann D, Authier FJ, Ponnelle T, Gray F, Levy Y. BK virus encephalitis in a patient with AIDS and lymphoma. AIDS (London, England). 2001;15:1196-9. 
36. Liang B, Tikhanovich I, Nasheuer HP, Folk WR. Stimulation of BK virus DNA replication by NFI family transcription factors. J Virol. 2012;86:3264-75. doi:10.1128/jvi.06369-11.

37. Lopes da Silva R. BK virus neurotropism. J Infect Public Health. 2011:4:103-4. doi:10.1016/j.jiph.2011.02.002.

38. Lopes da Silva R, Ferreira I, Teixeira G, Cordeiro D, Mafra M, Costa I, Bravo Marques JM, Abecasis M. BK virus encephalitis with thrombotic microangiopathy in an allogeneic hematopoietic stem cell transplant recipient Transpl Infect Dis. 2011;13:161-7. doi:10.1111/j.1399-3062.2010.00581.x.

39. Mangano S, Barbagallo A. Incontinentia pigmenti: clinical and neuroradiologic features. Brain Dev. 1993;15:362-6.

40. Markowitz RB, Dynan WS. Binding of cellular proteins to the regulatory region of BK virus DNA. J Virol. 1988;62:3388-98.

41. Moens U, Johansen T, Johnsen Jl, Seternes OM, Traavik T. Noncoding control region of naturally occurring BK virus variants: sequence comparison and functional analysis. Virus Genes. 1995;10:261-75.

42. Neu U, Stehle T, Atwood WJ. The Polyomaviridae: Contributions of virus structure to our understanding of virus receptors and infectious entry. Virology. 2009;384:389-99. doi:10.1016/j.virol.2008.12.021.

43. Olsen $\mathrm{GH}$, Hirsch $\mathrm{HH}$, Rinaldo $\mathrm{CH}$. Functional analysis of polyomavirus BK non-coding control region quasispecies from kidney transplant recipients. J Med Virol. 2009;81:1959-67. doi:10.1002/jmv.21605.

44. Price RW, Brew B, Sidtis J, Rosenblum M, Scheck AC, Cleary P. The brain in AIDS: central nervous system HIV-1 infection and AIDS dementia complex. Science. 1988;239:586-92.

45. Ryschkewitsch CF, Jensen PN, Major EO. Multiplex qPCR assay for ultra sensitive detection of JCV DNA with simultaneous identification of genotypes that discriminates non-virulent from virulent variants. J Clin Virol. 2013;57:243-8. doi:10.1016/j.jcv.2013.03.009.

46. Senegas A, Gautheron J, Maurin AG, Courtois G. IKK-related genetic diseases: probing NF-kappaB functions in humans and other matters. Cell Mol Life Sci. 2015;72:1275-87. doi:10.1007/s00018-014-1793-y.

47. Seo GJ, Fink LH, O'Hara B, Atwood WJ, Sullivan CS. Evolutionarily conserved function of a viral microRNA. J Virol. 2008;82:9823-8. doi:10.1128/jvi.01144-08.

48. Sharer LR. Pathology of HIV-1 infection of the central nervous system. A review. J Neuropathol Exp Neurol. 1992;51:3-11.

49. Shintaku M, Matsumoto R, Sawa H, Nagashima K. Infection with JC virus and possible dysplastic ganglion-like transformation of the cerebral cortical neurons in a case of progressive multifocal leukoencephalopathy. J Neuropathol Exp Neurol. 2000;59:921-9.

50. Smahi A, Courtois G, Vabres P, Yamaoka S, Heuertz S, Munnich A, Israel A, Heiss NS, Klauck SM, Kioschis P, Wiemann S, Poustka A, Esposito T, Bardaro T, Gianfrancesco F, Ciccodicola A, D'Urso M, Woffendin H, Jakins T, Donnai D, Stewart H, Kenwrick SJ, Aradhya S, Yamagata T, Levy M, Lewis RA, Nelson DL. Genomic rearrangement in NEMO impairs NF-kappaB activation and is a cause of incontinentia pigmenti. The International Incontinentia Pigmenti (IP) Consortium Nature. 2000;405:466-72. doi:10.1038/35013114.

51. Stoner GL, Alappan R, Jobes DV, Ryschkewitsch CF, Landry ML. BK virus regulatory region rearrangements in brain and cerebrospinal fluid from a leukemia patient with tubulointerstitial nephritis and meningoencephalitis. Am J Kidney Dis. 2002;39:1102-12. doi:10.1053/ajkd.2002.32795.

52. Tremolada S, Akan S, Otte J, Khalili K, Ferrante P, Chaudhury PR, Woodle ES, Trofe-Clark J, White MK, Gordon J. Rare subtypes of BK virus are viable and frequently detected in renal transplant recipients with BK virus-associated nephropathy. Virology. 2010;404:312-8. doi:10.1016/j.virol.2010.05.012.

53. Vallbracht A, Lohler J, Gossmann J, Gluck T, Petersen D, Gerth HJ, Gencic M, Dorries K. Disseminated BK type polyomavirus infection in an AIDS patient associated with central nervous system disease. Am J Pathol. 1993;143:29-39.

54. Vidal JE, Fink MC, Cedeno-Laurent F, Delbue S, Ferrante P, Dauar RF, Filho FB, Nogueira RS, Calore EE, Pannuti CS, Trujillo JR, de Oliveira AC. BK virus associated meningoencephalitis in an AIDS patient treated with HAART. AIDS Res Ther. 2007;4:13. doi:10.1186/1742-6405-4-13.

55. Voltz R, Jager G, Seelos K, Fuhry L, Hohlfeld R. BK virus encephalitis in an immunocompetent patient. Arch Neurol. 1996;53:101-3.

56. Watzke RC, Stevens TS, Carney Jr RG. Retinal vascular changes of incontinentia pigmenti. Arch Ophthalmol. 1976;94:743-6.

57. White MK, Safak M, Khalili K. Regulation of gene expression in primate polyomaviruses. J Virol. 2009;83:10846-56. doi:10.1128/jvi.00542-09.

58. Wuthrich C, Dang X, Westmoreland S, McKay J, Maheshwari A, Anderson MP, Ropper AH, Viscidi RP, Koralnik IJ. Fulminant JC virus encephalopathy with productive infection of cortical pyramidal neurons. Ann Neurol. 2009;65:742-8. doi:10.1002/ana.21619.

59. Zonana J, Elder ME, Schneider LC, Orlow SJ, Moss C, Golabi M, Shapira SK, Farndon PA, Wara DW, Emmal SA, Ferguson BM. A novel X-linked disorder of immune deficiency and hypohidrotic ectodermal dysplasia is allelic to incontinentia pigmenti and due to mutations in IKK-gamma (NEMO). Am J Hum Genet. 2000;67:1555-62. doi:10.1086/316914.

\section{Submit your next manuscript to BioMed Central and we will help you at every step:}

- We accept pre-submission inquiries

- Our selector tool helps you to find the most relevant journal

- We provide round the clock customer support

- Convenient online submission

- Thorough peer review

- Inclusion in PubMed and all major indexing services

- Maximum visibility for your research

Submit your manuscript at www.biomedcentral.com/submit
Ciomed Central 